\title{
The Impact of Covid-19 on the Incidence and Pattern of Oculofacial Injuries
}

\author{
AHMED GABER, M.D.*; HANY MAHMOUD, M.D.**; SEHAM A. ABOKRESHA, M.D.*** and \\ TAREK A. ABULEZZ, M.D.*
}

The Departments of Plastic Surgery*, Ophthalmology** and Public Health \& Community Medicine***, Faculty of Medicine, Sohag University, Egypt

\begin{abstract}
Background: Coronavirus Disease (Covid-19) has emerged as a global health problem by the end the 2019 . In response to this pandemic, a worldwide lockdown was implemented. In Egypt, the lockdown was implemented on March $25^{\text {th }}$ and lasted for about 3 months. In this retrospective study we tried to evaluate the impacts of Covid-19 lockdown on the incidence and pattern of oculofacial injuries the lockdown was effected in Egypt for 2 months in the period from April $1^{\text {st }}$ till the end of May 2020.
\end{abstract}

Patients and Methods: We reviewed the files of patients who were presented with oculofacial injuries to the Trauma Unit of Sohag University Hospital during the period from 1 April - 31 May in both 2019 and 2020 years. Demographic data of the patients, mode of trauma, definitive diagnosis and the management provided were collected and analyzed and the data of the two years were compared.

Results: A significant decrease in oculofacial injuries by 68.3 percent with a change in the mode of trauma and method of trauma. Males are more commonly the victims before and during the lockdown. The mean age before lockdown was $33.95 \pm 16.7$, while it was $27.38 \pm 18.6$ during lockdown. Significant increase in the assault from others in lockdown ( $p$ value $\leq 0.001$ ) with a decrease in motor car accidents (MCA) ( $p$-value $\leq 0.001$ ), significant increase in lid wounds, avulsed lid rupture globe and orbital fractures ( $p$-value $\leq 0.001)$.

Conclusion: Covid-19 lockdown resulted in significant change in the incidence and pattern of oculofacial injuries.

Key Words: Oculofacial trauma - Lockdown, Coronavirus Covid-19.

\section{INTRODUCTION}

Oculofacial trauma may lead to serious complications and represents a major emergency. It may involve only ocular and periocular areas but it is usually associated with other facial injuries. The most common causes are falling from height, motor car accident, sharp objects, and firearm injuries. Oculofacial injuries have a significant social and economic impact [1-4].
The pandemic of corona virus disease (Covid19) has emerged as a global health problem that results in a worldwide lockdown. This lockdown significantly affected the live of population and changed many aspects of their life, particularly outdoor activities and transportation. A question was raised concerning the incidence and pattern of oculofacial trauma during this period. Therefore, a retrospective study was designed to evaluate the impact of covid-19 lockdown on the incidence and pattern of oculofacial trauma.

Ocular injuries may be in the form of lid wounds, lacerations, avulsed lid, corneal abrasions, ulcers, rupture globe, hyphema, vitreous hemorrhage, or orbital fracture. It is usually associated with surrounding structures such as orbital bones, forehead, checks or even the head [5].

Coronavirus Disease 2019 (Covid-19) has emerged as a global health problem that induced a worldwide lockdown which has affected the population and changed many aspect of their life including the pattern and incidence of oculofacial trauma [6].

In this retrospective comparative study, we tried to evaluate the effect of Covid-19 on the oculofacial injuries by comparing the incidence and pattern of these injuries in patient admitted to the Trauma Unit of Sohag University Hospital (tertiary center) during the period of lockdown to those occurred in the same period of the last year 2019 .

\section{PATIENTS AND METHODS}

Records of patients presented with oculofacial injuries to the trauma center of the Sohag University Hospital during Covid-19 lockdown (from 1 April to 31 May 2020) were reviewed. That study was conducted after approval of the hospital administration to get access to these files. The following 
data were collected: Age, sex, type and mode of trauma and the management provided. The data was compared with the same period of 2019.

\section{Ethical considerations:}

The study was approved by the Medical Research Ethics Committee of the Faculty of Medicine, Sohag University.

Statistical analysis: The data collected were tabulated and analyzed using SPSS (Statistical Package for Social Science) version 25.

Two types of statistics were done:

Descriptive statistics: According to the type of data qualitative represented as number and percentage, quantitative continuous group represented by mean \pm SD.

Analytic statistics: The non-parametric Chisquare test $\left(\chi^{2}\right)$ was used to study the comparison and association between two qualitative variables that are not normally distributed.

\section{RESULTS}

A significant decrease in the number of cases was found. Total number of cases was 39 , which is $32.7 \%$ only of the total number of cases in the same 2-month period of the tear 2019 that was 123 cases. There was a change in the mode and type of trauma (Table 1) as well as the presenting diagnosis of the cases (Table 2).

The Mean age before lockdown is $33.95 \pm 16.7$ while it is $27.38 \pm 18.6$ during lockdown. Males were the common victims before and during the lockdown however, the percentage of female victims raised from $17.8 \%$ before the lockdown to $25.6 \%$ during lockdown (Fig. 1). There is significant increase in assault from others ( $p$-value $\leq 0.001$ ), and significant decrease in motor car accident MCA ( $p$-value $\leq 0.001)$. Significant increase in the lid wounds, avulsed lid, rupture globe and orbital fractures ( $p$-value $\leq 0.001)$ were also observed. These changes are shown in Figs. $(2,3)$.

The cases were managed by a team of Plastic and Ophthalmology Departments at the Sohag University Trauma Center. All infection control precautions with personal protection equipment (PPE) during examining the patient in the ER and during the surgical intervention then they were guaranteed.

Complete blood count (CBC), computed tomography chest (CT) and rapid test (Artron COVID19 IgG/IgM - Antibody Rapid Test Kit: Artron Laboratories Inc. Canada) were performed to all patients before any intervention. Six cases were confirmed to have Covid-19 infection.

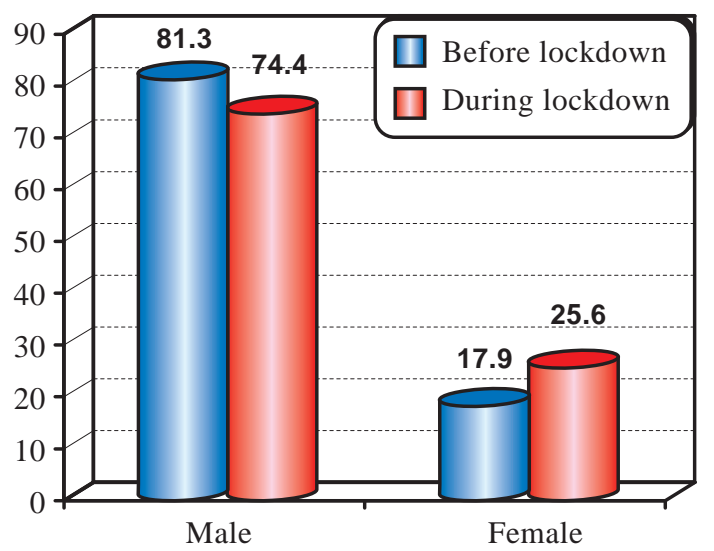

Fig. (1): Male to female ratio before and during lockdown with evident rise in female victim ratio during the lockdown.

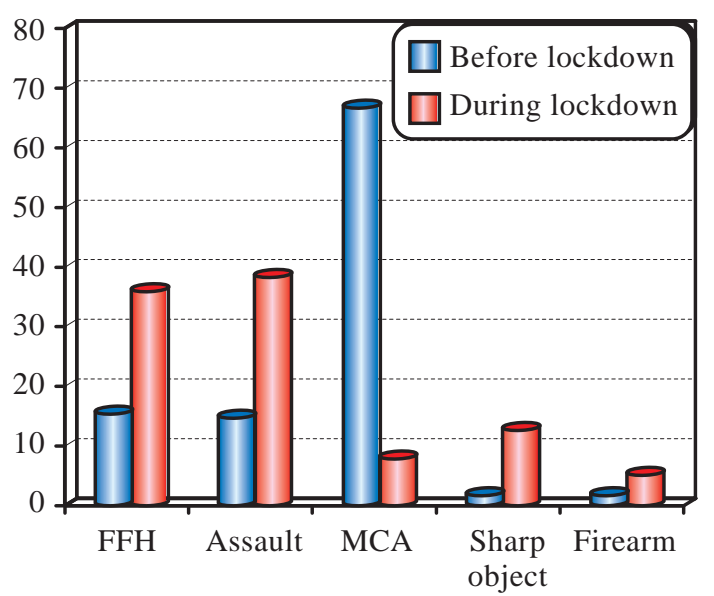

Fig. (2): The mode of trauma before and during lockdown.

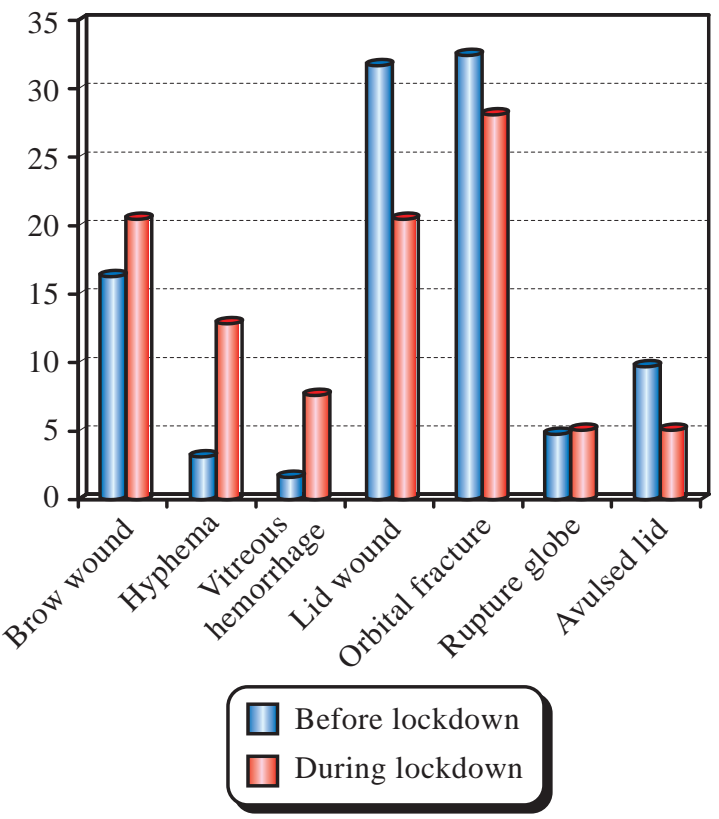

Fig. (3): The difference in the type of trauma before and during lockdown. 
Table (1): Mode of trauma before and during the lockdown.

\begin{tabular}{|c|c|c|c|}
\hline Mode trauma & $\begin{array}{l}\text { Before } \\
\text { lockdown }\end{array}$ & $\begin{array}{l}\text { During } \\
\text { lockdown }\end{array}$ & $\begin{array}{c}p- \\
\text { value }\end{array}$ \\
\hline Falling from height FFH & $19(15.44 \%)$ & $14(35.90 \%)$ & 0.003 \\
\hline Assault & $18(14.63 \%)$ & $15(38.46 \%)$ & 0.003 \\
\hline MCA & $82(66.67 \%)$ & $3(7.69 \%)$ & 0.000 \\
\hline Sharp object & $2(1.63 \%)$ & $5 \quad(12.82 \%)$ & 0.010 \\
\hline Firearm & $2(1.63 \%)$ & $2(5.13 \%)$ & 0.027 \\
\hline Total & 123 & 39 & \\
\hline
\end{tabular}

Table (2): Diagnosis of cases before and during the lockdown.

\begin{tabular}{lllll}
\hline Diagnosis & $\begin{array}{c}\text { Before } \\
\text { lockdown }\end{array}$ & $\begin{array}{c}\text { During } \\
\text { lockdown }\end{array}$ & $\begin{array}{c}p- \\
\text { value }\end{array}$ \\
\hline Brow wound & $20(16.26 \%)$ & 8 & $(20.51 \%)$ & 0.010 \\
Hyphema & $4(3.25 \%)$ & 5 & $(12.82 \%)$ & 0.010 \\
Vitreous hemorrhage & $2(1.63 \%)$ & 3 & $(7.69 \%)$ & 0.010 \\
Lid wound & $39(31.71 \%)$ & 8 & $(20.51 \%)$ & 0.005 \\
Orbital fracture & $40(32.52 \%)$ & $11(28.21 \%)$ & 0.027 \\
Rupture globe & $6(4.88 \%)$ & 2 & $(5.13 \%)$ & 1.000 \\
Avulsed lid & $12(9.75 \%)$ & 2 & $(5.13 \%)$ & 0.027 \\
\hline Total & 123 & 39 & \\
\hline
\end{tabular}

\section{DISCUSSION}

During the period of lockdown in Egypt which started on the 25th of March 2020 as a response to Covid-19 pandemic, all the regular ophthalmic and plastic surgery clinics in our hospital and all "cold" elective operations were suspended and the hospital was only accepting emergency and trauma cases. The traffic and transportation activity was decreased during the lockdown period, and this was reflected on the incidence of MCA which was decreased significantly. Covid-19 lockdown didn't only change the incidence and pattern of trauma but also it changed the whole life style of people as well [7]. Assault from others increased due to the psychological impact of lockdown and increased time to stay home with each other. MCA decreased due to restricted movement for all types of transportation [8].

The effect of the global pandemic of Covid-19 on the surgical practice has been an important title in many scientific journals [9-11]. One of the most important points in the plastic surgery practice is the way we should handle the trauma and emergency cases under such a global highly infectious virus pandemic [10]. In our series, the surgical management of confirmed cases was done under very strict protective precautions with the simplest necessary surgical procedures and the minimal manipulation and strict adherence to the guidelines of the infection control unit of the university hospital and maintenance of maximal personal protection. The emergency team was divided into two groups: Each group take two-week period on then the other group take over for the same period.

\section{Financial disclosure statement:}

There was no funding received for this work from any of the following organizations: National Institutes of Health (NIH); Howard Hughes Medical Institute (HHMI) or any other sources.

\section{Conflict of interest:}

Authors have no financial interests including products, devices, or drugs associated with this manuscript. There are no commercial associations that might pose or create a conflict of interest with information presented in this submitted manuscript such as consultancies, stock ownership, or patent licensing arrangements.

\section{REFERENCES}

1- De Juan E., Sternberg P. and Michels R.G.: Penetrating ocular injuries, types of injuries and visual results. Ophthalmology, 90 (11): 1318-1322. doi: 10.1016/S01616420 (83)34387-6, 1993.

2- Esmaeli B., Elner S.G., Schork M.A. and Elner V.M.: Visual outcome after penetrating trauma, a clinicopathological study. Ophthalmology, 102 (3): 393-400. Doi: 10.1016/s0161-6420(95)31009-3, 1995.

3- Georgouli T., Pountos I., Chang B.Y. and Giannoudis P.V.: Prevalence of ocular and orbital injuries in polytrauma patients. Eur. J. Trauma Emerg. Surg., 37 (2): 135-140. doi: 10.1007/s00068-010-0029-6, 2011.

4- Cheung C.A., Rogers-Martel M., Golas L., Chepurny A., Martel J.B. and Martel J.R.: Hospital-based ocular emergencies: Epidemiology, treatment, and visual outcomes. Am. J. Emerg. Med., 32 (3): 221-224. doi:10.1016/ j.ajem.2013.11.015, 2014.

5- Soni M., Khan I.U. and Jadoon Z.: The pattern of ocular trauma in patients at Govt. Naseerullah Khan Babar Memorial Hospital, Peshawar (A study from 2010-2014). Ophthalmol Update, 13 (4): 271-275, 2015.

6- Khanna R.C. and Honavar S.G.: All eyes on CoronavirusWhat do we need to know as ophthalmologists. Indian J. Ophthalmol., 68: 549-53, 2020.

7- Cao W., Fang Z., Hou G., Han M., Xu X., Dong J. and Zheng J.: The psychological impact of the COVID-19 epidemic on college students in China. Psychiatry Research, doi: 10.1016/j.psychres.2020.112934, 2020.

8- Asmundson G.J. and Taylor S.: Coronaphobia: Fear and the 2019-nCoV outbreak. J. Anx. Disord, 70 1-2. 10.1016/ j.janxdis.2020.102196, 2020.

9- Ozturk, Cemile Nurdan M.Da; Kuruoglu, Doga M.Db; Ozturk, Can M.Da; Rampazzo, Antonio M.D., Ph.Dc and Gurunian (Gurunluoglu), Raffi M.D., Ph.Dc: Plastic Surgery and the COVID-19 Pandemic, Annals of Plastic Surgery: August - Volume 85 - Issue 2S - p S155-S160 doi: 10.1097/SAP.0000000000002443, 2020. 
10- Hassan, Kareem M.D.; Prescher, Hannes M.D.; Wang, Frederick M.D.; Chang, David W. M.D. and Reid, Russell R. M.D., Ph.D.: Evaluating the Effects of COVID-19 on Plastic Surgery Emergencies, Annals of Plastic Surgery: August - Volume 85 - Issue 2S - p S161-S165 doi: 10.1097/SAP.0000000000002459, 2020.
11- Rajiv Agarwal, Maneesh Singhal, Vinay Kant Shankhdhar, Ravi Kumar Chittoria, Ranjit Kumar Sahu, Veena Singh and Ramesh Chandra: Plastic surgery practices amidst global COVID-19 pandemic: Indian consensus, Journal of Plastic, Reconstructive \& Aesthetic Surgery, ISSN 17486815, https://doi.org/10.1016/j.bjps.2020.08.003, 2020. 